\title{
Pneumatosis cystoides intestinalis associated with sunitinib and a literature review
}

\author{
Yong Suk Lee, Jae Joon Han, Si-Young Kim and Chi Hoon Maeng ${ }^{*}$ (D)
}

\begin{abstract}
Background: Pneumatosis cystoides intestinalis $(\mathrm{PCl})$ is a rare self-limiting condition characterized by air-filled cysts within intestinal walls. Diagnosis should be prudent because it can mimic pneumoperitoneum leading to unnecessary treatment such as surgical exploration. Although various drugs including anti-neoplastic agents have been suggested as etiologies, cases related to sunitinib are sparse. Because of the rarity of this unusual side effect by sunitinib, we report the case report.

Case presentation: A 68-year-old female with pancreatic neuroendocrine tumor who was treated with sunitinb for 4 months visited to our hospital complaining of severe diarrhea and mild abdominal discomfort. The abdominal $X$-ray showed subdiaphragmatic air mimicking intestinal perforation. After the meticulous evaluation including abdomino-pelvic computed tomography, the patient was diagnosed of $\mathrm{PCl}$ induced by sunitinib and fully recovered with conservative management.

Conclusions: It is important to note that $\mathrm{PCl}$ can develop after treatment with sunitinib because $\mathrm{PCl}$ has not been widely known as an adverse event caused by the agent. Furthemore, emergent surgery while sunitinib was administrated without adequate washout period can result in substantial surgical complications which could be avoided with the precise diagnosis.
\end{abstract}

Keywords: Pneumatosis cystoides intestinalis, Sunitinib, Perforation

\section{Background}

Pneumatosis cystoides intestinalis (PCI) is a rare condition characterized by air-filled cysts within intestinal walls. Although abdominal pain or distension can be associated with PCI, its symptoms are generally nonspecific and can be incidentally identified by routine imaging study $[1,2]$. PCI is categorized into either primary or secondary PCI. While primary PCI has an unknown etiology, various case reports of secondary PCI have suggested diverse causes [3]. Based on previous studies, physical causes such as intestinal obstruction or ischemia, pneumomediastinum extending to the abdominal cavity along with the great vessels, or infection could be associated with PCI. Anti-neoplastic agents have also been recently suggested as etiologic agents $[1,4]$.

Sunitinib is an oral multi-tyrosine kinase inhibitor targeting platelet-derived growth factor receptors

\footnotetext{
* Correspondence: mchihoon@khu.ac.kr

Division of Medical Oncology-Hematology, Department of Internal Medicine, Kyung Hee University Hospital, College of Medicine, Kyung Hee University, (02447) 23 Kyungheedae-ro, Dongdaemun-gu, Seoul, South Korea
}

(PDGFR $\alpha$ and PDGFR $\beta$ ), vascular endothelial growth factor receptors (VEGFR1, VEGFR2, and VEGFR3), FMS-like tyrosine kinase-3 (FLT3), colony-stimulating factor type 1 (CSF-1R), and glial cell-line-derived neurotrophic factor receptor (RET). The anti-tumor and anti-angiogenic activity of sunitinib have led to its wide use at several types of cancer. Common adverse events of sunitinib include hypertension, diarrhea, nausea, asthenia, fatigue, vomiting, hand-foot syndrome, and hematologic toxicity $[5,6]$. Herein, we report a rare case of PCI in a patient who was treated with sunitinib.

\section{Case presentation}

A 68-year-old female with well-differentiated pancreatic neuroendocrine tumor visited an outpatient clinic due to persistent diarrhea. She had been previously found to have unresectable pancreatic neuroendocrine tumor with hepatic metastases. After disease progression despite prior therapy of long-acting octreotide analogue and everolimus, she had been treated with sunitinib as a third-line chemotherapy. After 3 months of sunitinib 
treatment, she showed partial response on follow-up abdominal computed tomography (CT) but complained of watery diarrhea. There was no definite cause of the diarrhea. Although it was partially controlled by loperamide, diarrhea persisted for over 1 month. Colonoscopy revealed no abnormal findings. Given the possibility of diarrhea due to adverse effects of sunitinib, the patient was treated with a reduced dose of sunitinib $(25 \mathrm{mg} /$ day) and loperamide concomitantly. After a brief period of improved diarrhea, however, she returned to the hospital complaining of severe diarrhea for over 1 week.

A simple chest X-ray taken on admission showed subdiaphragmatic air on the right side of the upper abdomen (Fig. 1) with severe distension. This was an unexpected finding because the patient did not complain of any signs of intestinal perforation, such as abdominal pain, tenderness, or hemodynamic instability. She complained of diarrhea, mild fatigue, dyspepsia, and vague abdominal discomfort. Her vital signs were stable as follows: blood pressure $140 / 90 \mathrm{mmHg}$, body temperature $36.6{ }^{\circ} \mathrm{C}$, heart rate $78 / \mathrm{min}$, respiratory rate $20 / \mathrm{min}$. Blood tests showed no specific results. On physical examination, tympanic percussion on a distended abdomen and decreased bowel sounds were noted. Abdominal CT scan was performed to evaluate additional problems because her symptoms and signs were neither specific nor informative despite subdiaphragmatic air on chest X-ray. Abdominal CT scan showed diffuse airfilled cystic formation along with distal ileum and colon

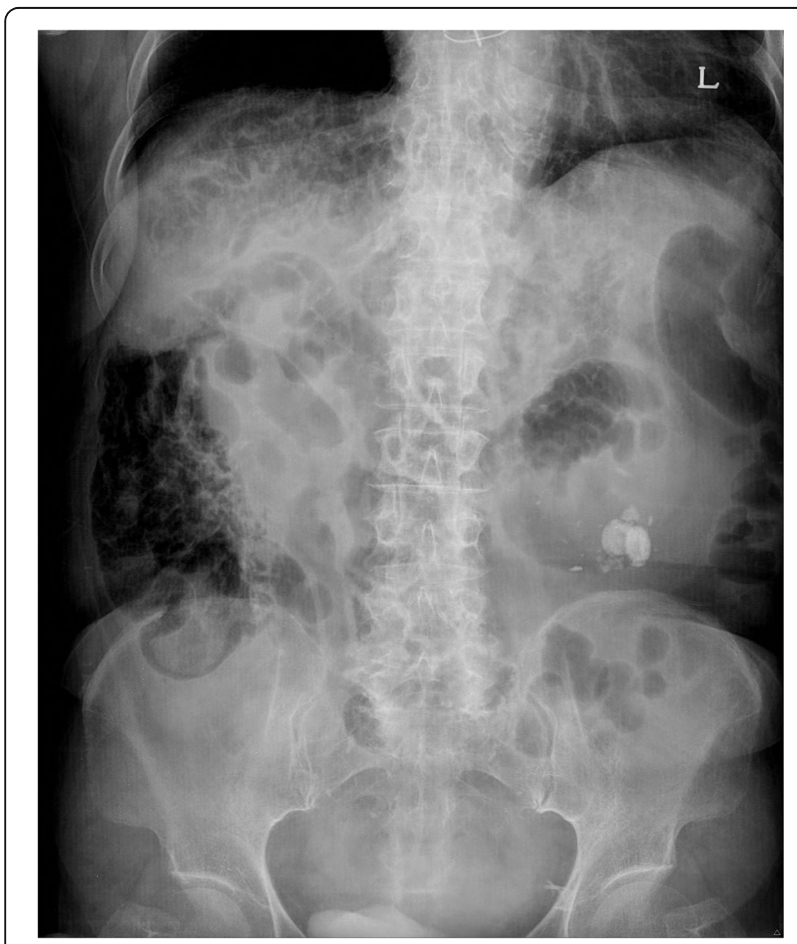

Fig. 1 Erect view of abdominal X-ray at initial presentation mimicking pneumoperitoneum (Fig. 2a, b). Although there was a large amount of air in the abdominal cavity on CT scan, it was along the bowel loop and confined to the intestinal wall rather than freely located. Divertucula were ruled out because the shape of air pocket was circular along with the luminal wall. Diverticulum is typically presented as a focal outpouching sac. Given the typical findings on abdominal CT, a diagnosis of PCI was made.

The patient received conservative management. Sunitinib was stopped since 1 day before admission and never reintroduced again. Supplemental oxygen was provided, and she was advised to avoid eating per os and provided with parenteral nutrition support for several days. Subsequent follow-up CT scans and abdominal X-ray showed improved gas contents within the bowel wall (Fig. 3). Two weeks later, she was completely recovered from PCI. Diarrhea was also improved a few days after discontinuation of sunitinib with conservative management such as hydration and loperamide.

\section{Discussion and conclusions}

Although the pathogenesis has not been fully established, various causes or clinical situations have been suggested to explain the development of PCI. They are classified as the following categories [1, 2, 7-10]: (1) mechanical irritation or increased intra-abdominal pressure caused by surgery, trauma, or colonoscopy that causes intraluminal air to penetrate into the bowel wall; (2) respiratory disease such as chronic obstructive pulmonary disease can result in pneumomediastinum by increased pulmonary alveolar pressure and rupture, and the trapped air can move into the abdominal cavity; (3) bacterial overgrowth in the lumen can cause increased intraluminal gas and pressure to penetrate through a disrupted or damaged mucosal barrier; (4) Disequilibrium of luminal gas composition and pressure causing supersaturation of gas, and resultantly forming air bubbles in the wall along with the bowel vasculatures.

Recently, chemotherapeutic agents have been reported as the cause of PCI. A case report of PCI in a patient after one session of cytotoxic chemotherapy (daunorubicin, vincristine, L-asparaginase, and prednisolone as an induction treatment) explained that chemotherapy might increase the risk of infection and result in intestinal bacterial overgrowth [4]. The effect of gas-forming bacteria on the bowel wall can lead to air-filled cysts within the wall, increasing mucosal friability and permeability. Although there was no evidence of bacterial infection such as enterocolitis, repeated mucosal irritation could damage the bowel wall. According to previous studies, air-filled cysts within the bowel wall can develop by movement of intraluminal air into the wall after mucosal injury [1]. Relatedly, the submucosa is the most common site of PCI among the layers of the bowel wall [1]. The 


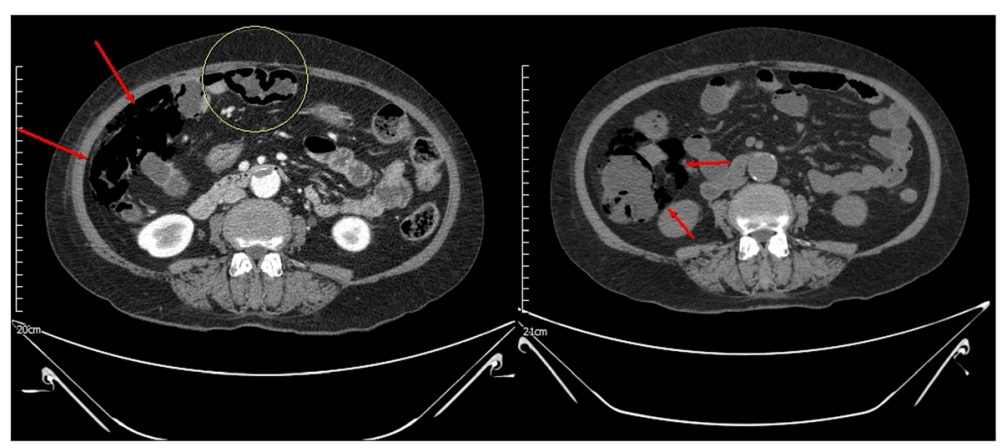

Fig. 2 Abdominal CT at initial presentation. Note the air collection within ileal loops and colonic wall on initial CT (Left). PCI was severe, thus air-containing cysts (arrows and circle) were distributed at both of mesenteric and anti-mesenteric border. On the follow-up CT (Right) taken 1 week later, improving PCI was observed. Cysts at mesenteric border and near mesenteric vessels were predominant (arrows)

rate of all grades of diarrhea has been reported to be up to $60 \%$, although diarrhea more severe than grade 3 develops less frequently $(<10 \%)[6,11]$. Taken together, these findings indicate that severe diarrhea caused by sunitinib can be associated with mucosal irritation and damage that contributes to PCI.

An interesting and more relaible theory of PCI known as "Counterperfusion supersaturation" can be another explanation for the development of PCI in this case. [8-10]. Component of air within cysts in patients with PCI mainly composed of hydrogen, nitrogen, and carbon dioxide [12]. In normal circumstance, gas pressure of hydrogen produced by intestinal bacteria and nitrogen diffused from blood stream by pulmonary gas exchange reaches equilibrium. Under certain conditions such as excessive hydrogen production due to bacterial overgrowth, pressure gradient could be high enough to result in gas supersaturation, giving rise to gas-containing cystic formation under

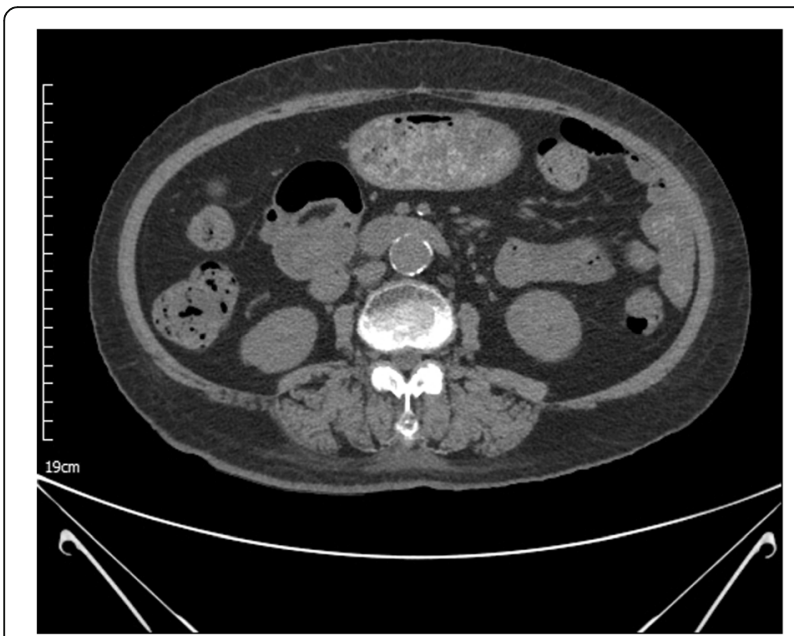

Fig. 3 Follow-up abdominal CT after 2 week shows nearly resolved state of $\mathrm{PCl}$ the influence of resistive index of colonic wall [8]. Although there was no clear evidence regarding this etiology associated with excessive hydrogen production including bacterial overgrowth, transient bowel inflammation with severe diarrhea might be related to such condition.

Furthermore, this theory gives another clue of relationship between PCI and its enhanced predisposition by antiangiogenic treatment. Sunitinib is a small molecule inhibitor mainly inhibiting VEGF receptors. Inhibition of angiogenesis may lead to decreased capillary density of the intestine. This could prevent efficient gas diffusion and exchange across the blood vessels and bowel lumen, leading to increase in gas pressure gradient predisposing gas supersaturation. Sunitinib treatment in our patient could be an explanation of possible diffusion barrier despite the fact that the patient did not have any medical history of vascular disease or chronic obstructive disease such as emphysema.

Besides, it is well known that anti-angiogenic therapy such as bevacizumab can result in gastrointestinal perforation [13]. In such situations, mucosal injury or microperforation of the wall could not be efficiently restored since blood supply via capillaries is disturbed [14]. Some authors have reported cases of sunitinibinduced intestinal perforation or PCI, associated with ischemic necrosis or pale-colored bowel $[15,16]$. Since PCI can be accompanied by perforation, although it remains to be explained further whether PCI always precedes intestinal perforation, it is assumed that the mechanisms of PCI and intestinal perforation caused by anti-angiogenic agents including sunitinib are similar to each other [16, 17]. However, bowel perforation caused by PCI is not common because intraluminal air trapped in the mucosal or submucosal layer should penetrate all layers of the intestine to develop pneumoperitoneum.

Cases of PCI with or without intestinal perforation associated with anti-angiogenic therapy are summarized in 
Table 1 Summarized case reports of $\mathrm{PCl}$ associated with anti-angiogenic therapy

\begin{tabular}{|c|c|c|c|c|c|c|c|c|c|c|}
\hline $\begin{array}{l}\text { Case Number } \\
\text { (Reference) }\end{array}$ & Sex/Age & Site & $\begin{array}{l}\text { Diagnostic } \\
\text { tool }\end{array}$ & $\begin{array}{l}\text { Underlying } \\
\text { disease }\end{array}$ & $\begin{array}{l}\text { Causative } \\
\text { agent }\end{array}$ & $\begin{array}{l}\text { Associated } \\
\text { symptoms }\end{array}$ & Perforation & Treatment & Outcome & $\begin{array}{l}\text { Time to } \\
\text { recovery }\end{array}$ \\
\hline 1 [14] & $M / 54$ & $\begin{array}{l}\text { Small } \\
\text { intestine }\end{array}$ & CT & $\begin{array}{l}\text { Pancreatic } \\
\text { neuroendocrine } \\
\text { tumor }\end{array}$ & $\begin{array}{l}\text { S1 plus } \\
\text { bevacizumab }\end{array}$ & Constipation & No & Observation & Resolved & 6 weeks \\
\hline $2[16]$ & $\begin{array}{l}\text { F/Not } \\
\text { described }\end{array}$ & Colon & CT, Biopsy & $\begin{array}{l}\text { Renal cell } \\
\text { carcinoma }\end{array}$ & Sunitinib & $\begin{array}{l}\text { Flank pain } \\
\text { and anuria }\end{array}$ & Yes & Operation & Resolved & NA \\
\hline 3 [16] & $\begin{array}{l}\text { F/Not } \\
\text { described }\end{array}$ & Colon & CT & $\begin{array}{l}\text { Renal cell } \\
\text { carcinoma }\end{array}$ & Sunitinib & $\begin{array}{l}\text { Diarrhea and } \\
\text { abdominal pain }\end{array}$ & Yes & Observation & Resolved & 12 weeks \\
\hline 4 [17] & $M / 73$ & Colon & CT & $\begin{array}{l}\text { Gastrointestinal } \\
\text { stromal tumor }\end{array}$ & Sunitinib & None & Yes & Observation & Resolved & 4 weeks \\
\hline 5 [18] & $\mathrm{F} / 40$ & $\begin{array}{l}\text { Small } \\
\text { intestine }\end{array}$ & CT & $\begin{array}{l}\text { Fibrolamellar } \\
\text { carcinoma }\end{array}$ & Sorafenib & $\begin{array}{l}\text { Abdominal } \\
\text { pain, fever }\end{array}$ & Yes & Observation & Resolved & 4 weeks \\
\hline $6[18]$ & $F / 48$ & $\begin{array}{l}\text { Small } \\
\text { intestine }\end{array}$ & $\mathrm{CT}$ & $\begin{array}{l}\text { Papillary thyroid } \\
\text { carcinoma }\end{array}$ & Sunitinib & $\begin{array}{l}\text { Diarrhea and } \\
\text { abdominal pain }\end{array}$ & No & Observation & Resolved & 4 weeks \\
\hline 7 [18] & $M / 68$ & $\begin{array}{l}\text { Small } \\
\text { intestine }\end{array}$ & CT & $\begin{array}{l}\text { Renal cell } \\
\text { carcinoma }\end{array}$ & Sunitinib & None & No & Operation & Resolved & NA \\
\hline 8 [15] & M/66 & $\begin{array}{l}\text { Small } \\
\text { intestine }\end{array}$ & CT & $\begin{array}{l}\text { Renal cell } \\
\text { carcinoma }\end{array}$ & Sunitinib & Abdominal pain & None & Operation & Resolved & NA \\
\hline
\end{tabular}

Table 1. Most cases were diagnosed based on X-ray and abdominal CT scans, like our patient. In general, a diagnosis of PCI can be made by imaging rather than endoscopy or invasive biopsy [1]. Among the eight cases, surgical intervention was performed in three patients because of suspicious bowel perforation or necrosis. However, there was no case that actually showed acute ischemia or bowel necrosis consistent with bowel perforation and panperitonitis. After retrospectively reviewing the clinical courses of each report, surgical exploration is considered unnecessary to diagnose or treat cases of PCI. PCI improved only with conservative management or close observation. The majority of asymptomatic patients spontaneously improve without any intervention [1]. Even if patients have related symptoms, conservative management including fasting, parenteral nutrition, or intestinal decompression is sufficient, with excellent prognosis. Occasionally, portal venous gas can be noted on CT findings in cases of mesenteric ischemia, and surgery may be considered if frank bowel infarction is suspected [7]. Based on such clinical knowledge, our patient was closely observed with conservative management and recovered in 2 weeks. The time to recovery was consistent with the cases summarized in Table 1.

There is an important point in terms of difference between PCI resulting from VEGF inhibitors and from other causes. Avoiding unnecessary surgical intervention is especially essential in PCI related to anti-angiogenic therapy. As shown in Table 1, surgical exploration is occasionally performed because PCI mimics bowel necrosis or panperitonitis. Since such an operation is performed in the emergency setting, an adequate washout period for anti-angiogenic therapy is not possible. This can lead to major postoperative co-morbidity such as delayed wound healing or hemorrhage.

In conclusion, with increasing use of VEGF inhibitors for various tumors, it is important to consider such uncommon adverse events because PCI was not mentioned as a drug-related adverse event in the previous clinical trials of these anti-neoplastic agents.

\section{Abbreviations}

CSF-1R: Colony-stimulating factor type 1; CT: Computed tomography; FLT3: FMS-like tyrosine kinase-3; PCl: Pneumatosis cystoides intestinalis; PDGFR: Platelet-derived growth factor receptors; RET: Glial cell-line-derived neurotrophic factor receptor; VEGFR: Vascular endothelial growth factor receptors

\section{Acknowledgements}

None

Funding

There was no specific source of funding for this study and manuscript.

\section{Availability of data and materials}

Not applicable.

Because this study is to present a case report, there was neither available dataset or materials to be shared publicly nor available repositories for it. However, authors will readily respond and give the patient's clinical information if requested, as long as it ensures that patient's personal information is not disclosed.

\section{Authors' contributions}

SK and $\mathrm{JJH}$ provided a guidance to manage the clinical situations, YSL was a major contributor in writing the manuscript. CHM was a main physician for the patient and supervised the written manuscript. All authos read and approved the final manuscript.

Ethics approval and consent to participate

IRB (The ethics committee) number: KHUH 2017-02-010.

IRB statement on consent: Approval.

IRB Membership List.

Sung-Ho Cha, Hee-Joo Lee, Weon Kim, Young Joon Choi, Mi Young Han,

Jong Seok Lee, Hong II Ki, Youngsoon Kim, Ami Yu, Won Sook Kim, Sunwoo

Seung Chul, Sang-Yong Lee, Myung Soon Kim. 


\section{Consent for publication}

We obtained the written informed consent from the patient in this report using the BMC cancer consent form. The informed consent obtained from the patient was for the publication of this case as well as clinical details and any accompanying images.

\section{Competing interests}

The authors declare that they have no competing interests.

\section{Publisher's Note}

Springer Nature remains neutral with regard to jurisdictional claims in published maps and institutional affiliations.

Received: 23 March 2017 Accepted: 31 October 2017

Published online: 09 November 2017

\section{References}

1. $\quad L L W$, Yang YS, Dou Y, Liu QS. A systematic analysis of pneumatosis cystoids intestinalis. World J Gastroenterol. 2013;19(30):4973-8.

2. Park JY, Yoon JY, Min SY, Hong SK, Park JS, Jang EJ, Baik HW, Park SJ. A case of recurrent pneumatosis cystoides intestinalis associated with recurrent pneumoperitoneum. Korean J Gastroenterol. 2007;50(3):188-92

3. Jamart J. Pneumatosis cystoides intestinalis. A statistical study of 919 cases. Acta Hepatogastroenterol. 1979;26(5):419-22.

4. Groninger E, Hulscher JB, Timmer B, Tamminga RY, Broens PM. Free air intraperitoneally during chemotherapy for acute lymphoblastic leukemia: consider pneumatosis cystoides intestinalis. J Pediatr Hematol Oncol. 2010; 32(2):141-3.

5. Valle JW, Faivre S, Hubner RA, Grande E, Raymond E. Practical management of sunitinib toxicities in the treatment of pancreatic neuroendocrine tumors. Cancer Treat Rev. 2014;40(10):1230-8.

6. Escudier B, Porta C, Bono P, Powles T, Eisen T, Sternberg CN, Gschwend JE, De Giorgi U, Parikh O, Hawkins R, et al. Randomized, controlled, doubleblind, cross-over trial assessing treatment preference for pazopanib versus sunitinib in patients with metastatic renal cell carcinoma: PISCES study. J Clin Oncol. 2014;32(14):1412-8.

7. Lee JY, Han HS, Lim SN, Shim YK, Choi YH, Lee OJ, Lee KH, Kim ST. Pneumatosis intestinalis and portal venous gas secondary to Gefitinib therapy for lung adenocarcinoma. BMC Cancer. 2012;12:87.

8. Donovan S, Cernigliaro J, Dawson N. Pneumatosis intestinalis: a case report and approach to management. Case Rep Med. 2011;2011:571387.

9. Florin THJ. Alkyl halides, super hydrogen production and the pathogenesis of pneumatosis cystoides coli. Gut. 1997;41:778-84.

10. Florin TH, Hills BA. Does counterperfusion supersaturation cause gas cysts in pneumatosis cystoides coli, and can breathing heliox reduce them? Lancet. 1995:345(8959):1220-2.

11. Stein A, Voigt W, Jordan K. Chemotherapy-induced diarrhea: pathophysiology, frequency and guideline-based management. Ther Adv Med Oncol. 2010;2(1):51-63.

12. Forgacs $\mathrm{P}$, Wright $\mathrm{PH}$, Wyatt $\mathrm{AP}$. Treatment of intestinal gas cysts by oxygen breathing. Lancet. 1973;1(7803):579-82.

13. Verheul HM, Pinedo HM. Possible molecular mechanisms involved in the toxicity of angiogenesis inhibition. Nat Rev Cancer. 2007;7(6):475-85.

14. Asmis TR, Chung KY, Teitcher JB, Kelsen DP, Shah MA. Pneumatosis intestinalis: a variant of bevacizumab related perforation possibly associated with chemotherapy related GI toxicity. Investig New Drugs. 2008;26(1):95-6.

15. Choi YA, Sim EH, Lee KE, Ko SY, Seo MJ, Yang YJ, Park JC, Park SY. A case of pneumatosis intestinalis associated with sunitinib treatment for renal cell carcinoma. Korean J Gastroenterol. 2013;61(6):347.

16. Flaig TW, Kim FJ, La Rosa FG, Breaker K, Schoen J, Russ PD. Colonic pneumatosis and intestinal perforations with sunitinib treatment for renal cell carcinoma. Investig New Drugs. 2009;27(1):83-7.

17. Jarkowski A 3rd, Hare R, Francescutti V, Wilkinson N, Khushalani N. Case report of pneumatosis intestinalis secondary to sunitinib treatment for refractory gastrointestinal stromal tumor. Anticancer Res. 2011;31(10):3429-32.

18. Coriat R, Ropert S, Mir O, Billemont B, Chaussade S, Massault PP, Blanchet B, Vignaux O, Goldwasser F. Pneumatosis intestinalis associated with treatment of cancer patients with the vascular growth factor receptor tyrosine kinase inhibitors sorafenib and sunitinib. Investig New Drugs. 2011;29(5):1090-3.

\section{Submit your next manuscript to BioMed Central and we will help you at every step:}

- We accept pre-submission inquiries

- Our selector tool helps you to find the most relevant journal

- We provide round the clock customer support

- Convenient online submission

- Thorough peer review

- Inclusion in PubMed and all major indexing services

- Maximum visibility for your research

Submit your manuscript at www.biomedcentral.com/submit 